\title{
Evaluation of a PCR-Reverse Blot Hybridization Assay to Identify Six Dermatophytes Predominant in the Republic of Korea
}

\author{
Hyunwoo Jin ${ }^{1, \$}$, Hyunjung Kim ${ }^{2, \$}$, Sunghyun Kim ${ }^{2,3}$, Yeonim Choi ${ }^{4}$, Hyeeun Bang ${ }^{2}$, \\ Sangjung Park ${ }^{5}$, Hyeyoung Wang ${ }^{6}$, Jang-Ho Lee ${ }^{7}$ In Ho Jang ${ }^{8}$, \\ Young-Kwon Kim ${ }^{9,10}$ and Hyeyoung Lee ${ }^{2, \dagger}$ \\ ${ }^{1}$ Department of Clinical Laboratory Science, College of Health Sciences, Catholic University of Pusan, \\ Busan 609-757, Korea, ${ }^{2}$ Department of Biomedical Laboratory Science, College of Health Sciences, \\ Yonsei University, Wonju 220-710, Korea, ${ }^{3}$ Institute for Life Science and Biotechnology, Yonsei University, \\ Seoul 120-749, Korea, ${ }^{4}$ Department of Biomedical Laboratory Science, Songho College, Hoengseong 225-704, \\ Korea, ${ }^{5}$ Department of Clinical Laboratory Science, College of Medical Science, Daegu Haany University, \\ Daegu 712-715, Korea, ${ }^{6}$ M\&D, Inc., Wonju Eco Environmental Technology Center, Wonju 220-710, Korea, \\ ${ }^{7}$ Department of Laboratory Medicine, Samsung Medical Center, Seoul 135-710, Korea, ${ }^{8}$ Department of \\ Biomedical Laboratory Science, College of Health Sciences, Sangji University, Wonju 220-702, Korea, \\ ${ }^{9}$ Department of Biomedical Laboratory Science, College of Medical Sciences, Konyang University, \\ Daejeon 302-718, Korea, ${ }^{10}$ Korean Collection of Medical Fungi (KCMF), Daejeon 302-718, Korea
}

Accurate and rapid diagnosis of dermatophytosis, a disease whose prevalence has been steadily increased, is important for successful treatment. Current laboratory methods for diagnosing dermatophytosis rely on $\mathrm{KOH}$ mount and fungal culture method. However, these methods have low sensitivity and are time-consuming ( $2 \sim 4$ weeks to diagnosis). In our previous study, a rapid molecular diagnostic assay (PCR-reverse blot hybridization assay, REBA) was developed to identify the following 6 main species of dermatophytes: Trichophyton rubrum, T. mentagrophytes, T. tonsurans, Microsporum canis, M. gypseum, and Epidermophyton floccosum. However, the REBA required more evaluation to validate its use in clinical examinations. The aim of the present study was to evaluate and validate the ability of the PCR-REBA to successfully identify dermatophytes in clinical isolates from dermatophytosis patients. Both conventional identification methods and the PCR-REBA were used to assess the presence of species of dermatophytes in 148 clinical isolates. The results of the two approaches were compared, and discrepancies between the two approaches were resolved by fungal ITS1 sequence analysis. T. rubrum was the most prevalent dermatophyte identified by conventional identification methods (118/148, 79.7\%) and the PCR-REBA (131/148, 88.4\%). The overall rate of consistency between conventional identification methods and the PCR-REBA was 79.0\% (117/148 samples). Fungal ITS1 sequence analysis showed that PCR-REBA results were correct for 93.5\% (29/31) of the discrepant samples. The PCR-REBA is rapid, sensitive, and highly specific compared with conventional identification methods. Thus, the PCR-REBA is a potentially useful tool for identifying dermatophytes in clinical settings.

Key Words: Dermatophytes, Identification, Molecular diagnosis, PCR-REBA

\footnotetext{
*Received: July 15, 2014 / Revised: August 7, 2014

Accepted: August 7, 2014

$\S_{\text {Equal contributors }}$

${ }^{\dagger}$ Corresponding author: Hyeyoung Lee. Mi-rae Hall 216, Yonsei University,

1 Yonseidae-gil, Wonju, Gangwon-do, 220-710, Korea.

Tel: +82-10-3227-8194, Fax: +82-33-760-2561

e-mail: hyelee@yonsei.ac.kr

CThe Korean Society for Biomedical Laboratory Sciences. All rights reserved.
}

\section{INTRODUCTION}

Dermatophytosis is caused by fungal infection, especially by superficial fungi on the skin, hair, and nails. These dermatophytes generally contain the genera Tricho- 
phyton, Microsporum, or Epidermophyton (Weitzman and Summerbell, 1995; Kim, 2006). About 10 to $20 \%$ of all dermatologic patients are diagnosed with dermatophytosis. The most prevalent dermatophytes in the Republic of Korea are Trichophyton rubrum, T. mentagrophytes, T. tonsurans, Microsporum canis, M. gypseum, and Epidermophyton floccosum. Together, these 6 dermatophytes comprise 99\% of all dermatophytosis-causing agents (Kim, 2006).

Although dermatophytosis is not a lethal disease, its occurrence has been increasing; thus, it has become more important in dermatologic clinics (Kim, 2006). Several factors have been proposed to increase the risk of fungal infection, including diabetes mellitus, aging, smoking, immune deficiency, and environmental factors (Haneke and Roseeuw, 1999; Gupta et al., 2000; Bristow and Spruce, 2009). Unlike other fungal infections, diagnosis and treatment of dermatophytosis are often difficult, especially when lesions are located under the fingernails or toenails (Weitzman and Summerbell, 1995; Gupta and Tu, 2006). In these cases, dermatophytosis is diagnosed and treated on the basis of clinical signs and symptoms (Weitzman and Summerbell, 1995). However, dermatophytosis diagnoses that are based only on clinical symptoms are estimated to be incorrect in approximately $50 \%$ of all cases (Graser et al., 2012). For anti-dermatophytosis therapy to be effective, accurate and rapid identification of dermatophytes is essential (Graser et al., 2012).

Current laboratory tests to identify dermatophytes mainly involve $\mathrm{KOH}$ mount and fungal culture methods (Weitzman and Summerbell, 1995). A typical microscopic method involves treating clinical specimens with potassium hydroxide $(\mathrm{KOH})$ and then examining them for fungal hyphae. These tests are rapid and simple; however, they have several limitations including low specificity, low sensitivity, and poor ability to perform species-level identification (Weitzman and Summerbell, 1995; Nazarian et al., 2012). Macroscopic identification mainly uses dermatophyte cultures to identify typical phenotypic and biochemical characteristics of each dermatophyte species (Weitzman and Summerbell, 1995; Mehlig et al., 2013). Fungal culture methods have higher specificity than $\mathrm{KOH}$ mount; however, cultures require at least 2 to 4 weeks for species-level identification (Paugam et al., 2013). Moreover, $\sim 30 \%$ of all clinical specimens cannot be cultured (Graser et al., 2012). A Furthermore, well-trained experts are required to interpret the complex phenotypes of cultured dermatophytes (Arabatzis et al., 2007).

In recent years, many molecular diagnostic methods have been developed to rapidly and accurately detect fungi. These diagnostic methods include techniques such as the polymerase chain reaction (PCR) (Brillowska-Dabrowska et al., 2010; Kim et al., 2011), the PCR-enzyme linked immunosorbent assay (ELISA) (Pankewitz et al., 2013), restriction fragment length pattern (RFLP) analysis (De Baere et al., 2010; Abastabar et al., 2014), matrix-assisted laser desorption ionization-time of flight mass spectrometry (MALDI-TOF MS) (Nenoff et al., 2012), and real-time PCR (Bergmans et al., 2010; Alexander et al., 2011; Bergman et al., 2013). In particular, the internal transcribed spacer (ITS) regions, ITS1 and ITS2, of the fungal ribosomal DNA gene complex have been used to identify various fungal species (Bergmans et al., 2010). Each of these molecular diagnostic methods has higher sensitivity and specificity, compared with conventional methods, for detecting and identifying dermatophytes (Khot and Fredricks, 2009). In particular, the PCR-reverse blot hybridization assay (PCR-REBA) has several advantages over other molecular assays in identifying dermatophyte species (Zeng et al., 2007; Bergmans et al., 2008; Kim et al., 2011). One advantage is that PCR-REBA use species-specific primers and specific probes, thus lowering their false-positive rates. Additionally, PCR-REBA can detect multiple dermatophyte species at once, and they also have high sensitivities, making them more suitable for clinical specimens (Bang et al., 2011; Kim et al., 2012).

In a previous study, we developed a new PCR-REBA to detect and identify the 6 most prevalent dermatophyte species: T. rubrum, T. mentagrophytes, T. tonsurans, $M$. canis, M. gypseum, and E. floccosum (Kim et al., 2011). Our PCR-REBA targeted the ITS1 region with dermatophytespecific oligonucleotide probes, and was shown to be highly sensitive. However, our PCR-REBA needed to be evaluated with clinical isolates in order to support its use in routine clinical examinations. Therefore, in this study, we used our previously developed PCR-REBA approach to identify 6 
dermatophyte species in 148 clinical isolates cultured from various clinical specimens.

\section{MATERIALS AND METHODS}

\section{Clinical isolates}

Various types of clinical samples were obtained from 148 dermatophytosis patients who had been attended at the Department of Laboratory Medicine, Samsung Medical Center (Seoul, Republic of Korea) between January 2011 and December 2011. All clinical isolates were deposited and recultured at the Korean Collection of Medical Fungi (KCMF, Daejeon, Republic of Korea) for PCR-REBA evaluation.

\section{Potassium hydroxide (KOH) examination}

To detect hyphae in clinical specimens, the $\mathrm{KOH}$ test was performed with various types of clinical specimens including nail, skin, and other specimens (Table 1). Briefly, clinical samples were placed on a slide with 1 to 2 drops of $\mathrm{KOH}$ solution (10\%). A cover slip was placed on the slide, and the slide was put into a humid incubator for at least 2 hr. After this incubation, the morphology of the remaining fungal hyphae was observed under a microscope by trained staff at Samsung Medical Center (Seoul, Republic of Korea).

\section{Dermatophytes culture}

Clinical specimens, including nail fragments and skin tissues, were inoculated onto Sabouraud Dextrose Agar (SDA) medium (Difco Laboratories, Detroit, MI, USA). To prevent bacterial and nondermatophytic fungal growth, 400 $\mathrm{mg} / \mathrm{L}$ cycloheximide (inhibitor of most saprobic molds) was added to the medium. Inoculated medium was incubated at $26^{\circ} \mathrm{C}$ in a humid environment for 2 to 4 weeks. Fungal colonies that took over 4 weeks to appear on the medium were excluded from this study.

\section{Fungal genomic DNA extraction}

Genomic DNA was extracted from cultured clinical isolates using the i-genomic BYF DNA Extraction Mini Kit (Intron Biotechnology Inc., Seoul, Republic of Korea) according to the manufacturer's instructions. Briefly, SDA medium containing cultured dermatophytes was cut into 2 or 3 pieces that were transferred to $15 \mathrm{~mL}$ conical tubes. Tubes were then vortexed vigorously after the addition of 2 $\mathrm{mL}$ phosphate buffered saline. Dermatophyte suspensions were spun by centrifugation at 13,000 x $\mathrm{g}$ for $5 \mathrm{~min}$, and the resultant supernatants were collected in new $2.0 \mathrm{~mL}$ Eppendorf tubes. Pretreated samples were incubated with MP buffer and $300 \mu \mathrm{g}$ lysozyme at $37^{\circ} \mathrm{C}$ for $15 \mathrm{~min}$. Tubes were mixed by inversion several times throughout this incubation. At the end of the incubation, MG buffer, $20 \mu \mathrm{g}$ proteinase K, and $10 \mu \mathrm{g}$ RNase A were added. Samples were lysed by vortexing, and the resultant lysates were incubated at $65^{\circ} \mathrm{C}$ for $30 \mathrm{~min}$. After complete lysis, MB buffer was added, tubes were gently mixed by inversion, and $80 \%$ ethanol was added. After gentle mixing, lysates were transferred to spin columns and spun by centrifugation at $13,000 \mathrm{x} g$ for $1 \mathrm{~min}$. Filtered flow-through solutions were discarded, and MW buffer was added to the spin columns. The columns were spun by centrifugation at $13,000 \mathrm{x} g$ for $1 \mathrm{~min}$ and the filtered flow-through solutions were discarded. Finally, the spin columns were placed in new $2.0 \mathrm{~mL}$ Eppendorf tubes, and ME buffer was added to the column membranes. After incubating for $1 \mathrm{~min}$, the tubes were spun by centrifugation at $13,000 \mathrm{x}$ g for $1 \mathrm{~min}$. Eluted genomic DNA samples were stored at $-20^{\circ} \mathrm{C}$ until PCR-REBAs were performed.

\section{PCR-REBA}

To identify dermatophytes, biotin-labeled oligonucleotide primers were used in nested PCR to amplify the ITS1 region as previously described. Cycling PCR conditions were as follows: initial denaturation, $5 \mathrm{~min}$ at $95^{\circ} \mathrm{C}$; initial PCR, 10 cycles of $30 \mathrm{sec}$ at $95^{\circ} \mathrm{C}$ for denaturation and $30 \mathrm{sec}$ at $65^{\circ} \mathrm{C}$ for primer annealing and extension; nested PCR, 40 cycles of $30 \mathrm{sec}$ at $95^{\circ} \mathrm{C}$ for denaturation and $30 \mathrm{sec}$ at $60^{\circ} \mathrm{C}$ for primer annealing and extension; final extension, $72^{\circ} \mathrm{C}$ for $7 \mathrm{~min}$.

REBA was performed after target amplification by thermocycling. Briefly, PCR products were denatured in $2 \mathrm{X}$ SSPE (150 mM NaCl, 10 mM NaH${ }_{2} \mathrm{PO}_{4}, 1$ mM EDTA)/ $0.1 \%$ SDS and incubated with REBA membrane strips at $25^{\circ} \mathrm{C}$ for $30 \mathrm{~min}$. Following two washes in $2 \mathrm{X} \mathrm{SSPE} / 0.5 \%$ 
SDS at $54^{\circ} \mathrm{C}$ for $10 \mathrm{~min}$, the strips were incubated with streptavidin-conjugated alkaline phosphatase in 2X SSPE/ $0.5 \%$. Next, the strips were washed twice with wash buffer at $25^{\circ} \mathrm{C}$ for $1 \mathrm{~min}$ and twice with $2 \mathrm{X} \mathrm{SSPE}$ at $25^{\circ} \mathrm{C}$ for 1 min. Hybridized amplicons harboring biotin-incorporated primers were detected by incubating REBA strips with nitro blue tetrazolium chloride and 5-bromo-4-chloro-3indolyl phosphate in $100 \mathrm{mM}$ Tris/ $\mathrm{HCl}(\mathrm{pH} 9.5) / 100 \mathrm{mM}$ $\mathrm{NaCl} / 50 \mathrm{mM} \mathrm{MgCl}_{2}$. Dermatophyte identification was performed by assessing the extent of amplicon hybridization to the dermatophyte-specific oligonucleotide probes.

\section{Sequence analysis}

In total, 31 samples exhibited discrepant results between conventional identification methods and PCR-REBA. The sequences of these samples were analyzed by Xenotech Company (Daejeon, Republic of Korea) to determine the specificity of each assay. Prior to sequence analysis, PCR was performed using primer pairs amplifying the fungal ITS1 region, in addition to portions of the $18 \mathrm{~S}$ rRNA and 5.8S rRNA sequences.

\section{RESULTS}

\section{Clinical specimens and clinical diagnosis}

Among 148 isolates, 76 (51.4\%), 70 (47.3\%), and 2 $(1.3 \%)$ were isolated from skin, nail, and other specimens, respectively $<$ Insert Table $1>$. Of 148 enrolled patients, 77, 17,8 , and 7 were diagnosed with tinea unguium, tinea pedis, tinea corporis, and tinea cruris; 39 patients were diagnosed with other superficial diseases (Table 1).

\section{Results of conventional identification methods}

All 148 clinical isolates were isolated on SDA and identified by conventional methods including $\mathrm{KOH}$ tests, LPCB assays, and microscopic and macroscopic interpretation. Among 148 cases, 118 (79.7\%), 15 (10.1\%), 9 (6.1\%), $1(0.7 \%)$, and $1(0.7 \%)$ were identified by conventional identification methods as T. rubrum, Trichophyton sp., $T$. mentagrophytes, Microsporum canis, and Acremonium sp., respectively (Fig. 1A). In addition, 4 clinical isolates (2.7\%) were identified as unidentified molds.
Table 1. Distribution of clinical specimens from Samsung Medical Center during 2011

\begin{tabular}{llc}
\hline $\begin{array}{c}\text { Type of clinical } \\
\text { specimens }\end{array}$ & Type of infection site & $\begin{array}{c}\text { No. of } \\
\text { samples (\%) }\end{array}$ \\
\hline & Tinea unguium & $30(39.5)$ \\
Skin $(\mathrm{n}=76)$ & Tinea pedis & $13(17.6)$ \\
& Tinea corporis & $8(10.5)$ \\
& Tinea cruris & $3(3.9)$ \\
& Other diseases & $22(28.5)$ \\
\hline \multirow{3}{*}{ Nail $(\mathrm{n}=70)$} & Tinea unguium & $46(65.7)$ \\
& Tinea pedis & $4(5.7)$ \\
& Tinea cruris & $4(5.7)$ \\
& Other diseases & $16(22.9)$ \\
\hline \multirow{2}{*}{ Other $(\mathrm{n}=2)$} & Tinea unguium & $1(50.0)$ \\
& Other diseases & $1(50.0)$ \\
\hline Total & \multicolumn{2}{c}{$148(100)$} \\
\end{tabular}

\section{PCR-REBA results}

Dermatophytes were also identified by PCR-REBA using genomic DNA samples from the same 148 clinical isolates. All 148 samples showed a positive signal with the AP control probe and a pan-fungus probe. Of 148 cases, 131 (88.4\%), 14 (9.5\%), 1 (0.7\%), 1 (0.7\%), and 1 (0.7\%) were identified by PCR-REBA as T. rubrum, T. mentagrophytes, Trichophyton sp., M. canis, and other fungi, respectively (Fig. 1B).

\section{Comparison of results obtained from conventional identification methods and PCR-REBA}

Among 118 clinical isolates identified as T. rubrum by conventional identification methods, 108 (91.6\%), 9 (7.6\%), and $1(0.8 \%)$ were identified as T. rubrum, T. mentagrophytes, and Trichophyton sp. by the PCR-REBA. The concordance between conventional identification methods and the PCRREBA for identifying T. rubrum was $91.6 \%$. Among 9 clinical isolates identified as T. mentagrophytes by conventional identification methods, 4 (44.4\%), 4 (44.4\%), and 1 (11.2\%) were identified as T. mentagrophytes, T. rubrum, and other fungi by the PCR-REBA technique. The concordance for identifying $T$. mentagrophytes between the two approaches was $44.4 \%$. Of 15 cases identified as Trichophyton sp. by conventional identification methods, 
A

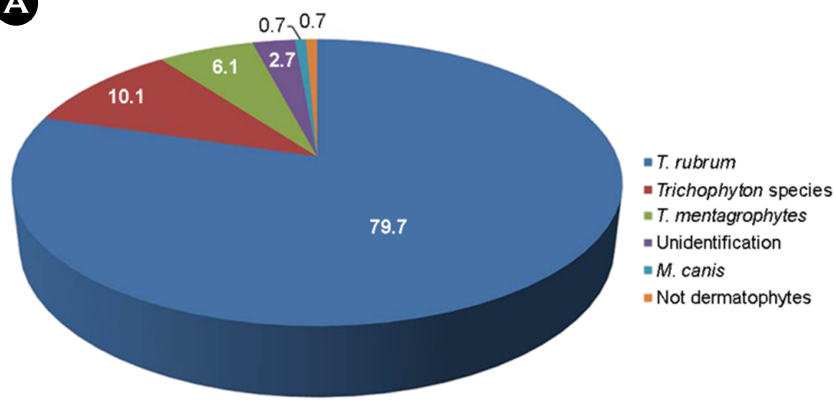

B

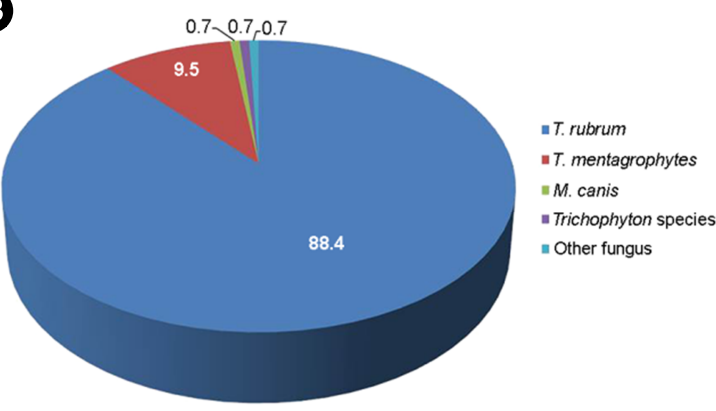

Fig. 1. Comparison of dermatophyte distributions as identified by conventional methods and PCR-REBA. (A) Clinical isolates identified by conventional methods. (B) Clinical isolates identified by PCR-REBA.

Table 2. Comparison of isolates identified by microscopic methods and PCR-REBA

\begin{tabular}{|c|c|c|c|}
\hline \multicolumn{2}{|c|}{ Conventional methods } & \multicolumn{2}{|c|}{ PCR-REBA } \\
\hline Species & No. & Species & No. $(\%)$ \\
\hline \multirow[t]{3}{*}{ Trichophyton rubrum } & 118 & Trichophyton rubrum & $108(91.6)$ \\
\hline & & Trichophyton mentagrophytes & $9(7.6)$ \\
\hline & & Trichophyton sp. & $1(0.8)$ \\
\hline \multirow[t]{3}{*}{ Trichophyton mentagrophytes } & 9 & Trichophyton mentagrophytes & $4(44.4)$ \\
\hline & & Trichophyton rubrum & $4(44.4)$ \\
\hline & & Other & $1(11.2)$ \\
\hline \multirow[t]{2}{*}{ Trichophyton sp. } & 15 & Trichophytonrubrum & $14(93.3)$ \\
\hline & & Trichophyton mentagrophytes & $1(6.7)$ \\
\hline Microsporum canis & 1 & Microsporum canis & $1(100.0)$ \\
\hline Acremonium sp. & 1 & Trichophyton rubrum & $1(100.0)$ \\
\hline Unidentified mold form fungi & 4 & Trichophyton rubrum & $4(100.0)$ \\
\hline Total & 148 & Total & 148 \\
\hline
\end{tabular}

$14(93.3 \%)$ and $1(6.7 \%)$ were identified as T. rubrum and T. mentagrophytes by the PCR-REBA technique. One clinical isolate was identified as $M$. canis by both identification approaches; therefore, the concordance for $M$. canis identification between the two approaches was $100 \%$. One clinical isolate was identified as Acremonium sp. by conventional identification methods; however, this isolate was identified as T. rubrum by the PCR-REBA (Table 2).

\section{Results of fungal ITS1 sequence analysis}

To resolve the discrepant results obtained by the two approaches, sequence analysis was performed on the 31 cases whose results differed by conventional identification methods and the PCR-REBA technique. For sequence analysis, the entire fungal ITS1 region was amplified by PCR and then analyzed. Of the 31 samples, 31 (93.5\%; 29/31) were identified correctly by PCR-REBA (Table 3 ). One sample was identified as T. erinacei by ITS1 sequence analysis, but this sample could not be identified at the species level (Trichophyton sp.) due to the lack of a suitable T. erinacei-specific probe. Another sample was identified as Arthroderma benhamiae by ITS1 sequence analysis, but this sample also could not be identified at the species level (other fungus) due to the lack of a suitable $A$. benhamiaespecific probe. 
Table 3. ITS1 sequence analysis of clinical isolates with discrepant results

\begin{tabular}{|c|c|c|c|c|c|}
\hline \multicolumn{2}{|l|}{ Conventional methods } & \multicolumn{2}{|l|}{ PCR-REBA } & \multicolumn{2}{|l|}{ Sequence analysis } \\
\hline Species & No. & Species & No. & Species & No. \\
\hline \multirow[t]{2}{*}{ Trichophyton rubrum } & 10 & Trichophyton mentagrophytes & 9 & Trichophyton mentagrophytes & 9 \\
\hline & & Trichophyton sp. & 1 & Trichophyton erinacei & 1 \\
\hline \multirow[t]{2}{*}{ Trichophyton mentagrophytes } & 5 & Trichophyton rubrum & 4 & Trichophyton rubrum & 4 \\
\hline & & Other & 1 & Arthroderma benhamiae & 1 \\
\hline \multirow[t]{2}{*}{ Trichophyton sp. } & 15 & Trichophyton mentagrophytes & 1 & Trichophyton mentagrophytes & 1 \\
\hline & & Trichophyton rubrum & 14 & Trichophyton rubrum & 14 \\
\hline Acremonium sp. & 1 & Trichophyton rubrum & 1 & Trichophyton rubrum & 1 \\
\hline Total & 31 & Total & 31 & Total & 31 \\
\hline
\end{tabular}

\section{DISCUSSION}

Conventional diagnostic methods, including microscopic and macroscopic methods, are widely used for dermatophyte identification. In microscopic methods, dermatophyte hyphae are directly detected after $\mathrm{KOH}$ (Weitzman and Summerbell, 1995). Macroscopic methods detect phenotypic or biochemical characteristics of cultured dermatophyte isolates. However, these methods have many limitations which hinder the accurate and rapid identification of dermatophytes. Conventional methods have low sensitivity and specificity; furthermore, they are time-consuming because they require long periods to culture dermatophytes and involve subjective evaluation by examiners.

To overcome these limitations, many molecular diagnostic methods have been developed. Previously, we developed the PCR-REBA and used it to identify 6 dermatophytes predominant in the Republic of Korea (Kim et al., 2011). The limit of detection for our assay was $1 \mathrm{fg}$ of dermatophyte (T. rubrum) genomic DNA. Our assay has extremely high sensitivity, since it uses two pairs of primers in a nested PCR reaction. Moreover, our assay uses a lower concentration of oligonucleotide probes, making it more sensitive and costeffective than assays developed in other studies (Bergmans et al., 2008).

The aim of this study was to evaluate and validate our PCR-REBA with 148 clinical isolates, and to compare these PCR-REBA results to those obtained by conventional identification methods. The most prevalent dermatophyte found in this study was T. rubrum (88.4\%), followed by $T$. mentragrophytes $(9.5 \%)$ and $M$. canis $(0.7 \%)$. These findings are consistent with a previous study which also reported that T. rubrum was the most common isolate (Kim, 2006). The agreement between our study and others indicates that T. rubrum is the major causative agent of dermatophytosis in the Republic of Korea. Nearly all clinical isolates (146, 98.6\%) were identified on the dermatophyte species level by PCR-REBA, and $87.1 \%$ (129/148) were identified on the dermatophyte species level by conventional identification methods. Although one sample was identified as nondermatophyte by conventional identification methods, it was identified as T. rubrum by the PCR-REBA. These data indicate that PCR-REBA is more suitable for identifying dermatophytes on the species level than conventional identification methods.

Clinical isolates with discrepant results between PCRREBA and conventional identification methods were further investigated by fungal ITS1 sequence analysis. Almost all of the ITS1 sequence results (29/31) agreed with the PCRREBA results. One of the PCR-REBA results that did not agree with the sequencing data was identified on the dermatophyte genus level (Trichophyton sp.) by PCR-REBA, but it was identified as $T$. erinacei by fungal ITS1 sequence analysis. This discrepancy can probably be ascribed to the lack of a suitable $T$. erinacei-specific oligonucleotide probe for PCR-REBA. T. erinacei is now classified as a familiar member of T. mentagrophytes (De Baere et al., 2010). The 
other PCR-REBA result that did not agree with its corresponding ITS1 sequencing result showed a positive signal only with the pan-fungus specific probe by PCR-REBA; however, ITS1 sequence analysis identified this sample as Arthroderma benhamiae. Again, this discrepancy can probably be ascribed to the lack of a suitable Arthroderma benhamiae-specific oligonucleotide probe for PCR-REBA.

Overall, the results presented here demonstrate that PCRREBA identifies the 6 most common dermatophytes in clinical isolates more accurately and rapidly than conventional identification methods. However, further evaluation with additional clinical specimens will no doubt help establish the usefulness of our assay.

\section{REFERENCES}

Abastabar M, Mirhendi H, Rezaei-Matehkolaei A, Shidfar MR, Kordbacheh P, Makimura K. Restriction Analysis of betaTubulin Gene for Differentiation of the Common Pathogenic Dermatophytes. J Clin Lab Anal. 2014. 28: 91-96.

Alexander CL, Shankland GS, Carman W, Williams C. Introduction of a dermatophyte polymerase chain reaction assay to the diagnostic mycology service in Scotland. Br J Dermatol. 2011. 164: 966-972.

Arabatzis M, Bruijnesteijn van Coppenraet LE, Kuijper EJ, de Hoog GS, Lavrijsen AP, Templeton K, van der Raaij-Helmer EM, Velegraki A, Graser Y, Summerbell RC. Diagnosis of common dermatophyte infections by a novel multiplex real-time polymerase chain reaction detection/identification scheme. Br J Dermatol. 2007. 157: 681-689.

Bang H, Park S, Hwang J, Jin H, Cho E, Kim DY, Song T, Shamputa IC, Via LE, Barry CE, 3rd, Cho SN, Lee H. Improved rapid molecular diagnosis of multidrug-resistant tuberculosis using a new reverse hybridization assay, REBA MTB-MDR. J Med Micrrobiol. 2011. 60: 1447-1454.

Bergman A, Heimer D, Kondori N, Enroth H. Fast and specific dermatophyte detection by automated DNA extraction and real-time PCR. Clin Microbiol Infect. 2013. 19: E205-211.

Bergmans AM, Schouls LM, van der Ent M, Klaassen A, Bohm N, Wintermans RG. Validation of PCR-reverse line blot, a method for rapid detection and identification of nine dermatophyte species in nail, skin and hair samples. Clin Microbiol Infect. 2008. 14: 778-788.

Bergmans AM, van der Ent M, Klaassen A, Bohm N, Andriesse
GI, Wintermans RG. Evaluation of a single-tube real-time PCR for detection and identification of 11 dermatophyte species in clinical material. Clin Microbiol Infect. 2010. 16: 704-710.

Brillowska-Dabrowska A, Nielsen SS, Nielsen HV, Arendrup MC. Optimized 5-hour multiplex PCR test for the detection of tinea unguium: performance in a routine PCR laboratory. Med Mycol. 2010. 48: 828-831.

Bristow IR, Spruce MC. Fungal foot infection, cellulitis and diabetes: a review. Diabet Med. 2009. 26: 548-551.

De Baere T, Summerbell R, Theelen B, Boekhout T, Vaneechoutte M. Evaluation of internal transcribed spacer 2-RFLP analysis for the identification of dermatophytes. J Med Microbiol. 2010. 59: 48-54.

Graser Y, Czaika V, Ohst T. Diagnostic PCR of dermatophytes-an overview. J Dtsch Dermatol Ges. 2012. 10: 721-726.

Gupta AK, Gupta MA, Summerbell RC, Cooper EA, Konnikov N, Albreski D, MacDonald P, Harris KA. The epidemiology of onychomycosis: possible role of smoking and peripheral arterial disease. J Eur Acad Dermatol Venereol. 2000. 14: 466 -469 .

Gupta AK, Tu LQ. Dermatophytes: diagnosis and treatment. Journal of the American Academy of Dermatology. 2006. 54: 1050 -1055 .

Haneke E, Roseeuw D. The scope of onychomycosis: epidemiology and clinical features. Int J Dermatol. 1999. 38 Suppl 2: 7-12.

Kim H, Jin H, Kim S, Wang HY, Choi Y, Bang H, Park JS, Lee JH, Won Y, Ahn KJ, Kim YK, Lee H. PCR-reverse Blot Hybridization Assay for Species Identification of Dermatophytes. Korean J Med Mycol. 2011. 16: 86-98.

Khot PD, Fredricks DN. PCR-based diagnosis of human fungal infections. Expert Rev Anti Infect Ther. 2009. 7: 1201-1221.

Kim JY, Choe YB, Ahn KJ, Lee YW. Identification of dermatophytes using multiplex polymerase chain reaction. Ann Dermatol. 2011. 23: 304-312.

Kim KH. Changing Patterns of Dermatophytosis and Its Causative Agents according to Social and Economic Developments in Korea. Kor J Med Mycol. 2006. 11: 1-12.

Kim S, Lee D, Park S, Kim TU, Jeon BY, Park KH, Lee H. REBA HPV-ID(R) for efficient genotyping of human papillomavirus in clinical samples from Korean patients. J Med Virol. 2012. 84: 1248-1253.

Mehlig L, Garve C, Ritschel A, Zeiler A, Brabetz W, Weber C, Bauer A. Clinical evaluation of a novel commercial multiplexbased PCR diagnostic test for differential diagnosis of 
dermatomycoses. Mycoses. 2013.

Nazarian RM, Due B, Deshpande A, Duncan LM, Misdraji J. An improved method of surgical pathology testing for onychomycosis. J Am Acad Dermatol. 2012. 66: 655-660.

Nenoff P, Erhard M, Simon JC, Muylowa GK, Herrmann J, Rataj W, Graser Y. MALDI-TOF mass spectrometry - a rapid method for the identification of dermatophyte species. Med Mycol. 2013. 51: 17-24.

Pankewitz F, Nenoff P, Uhrlass S, Bezold G, Winter I, Graser Y. Development of a novel polymerase chain reaction-enzymelinked immunosorbent assay for the diagnosis of Trichophyton rubrum onychomycosis. Br J Dermatol. 2013. 168: 1236
-1242 .

Paugam A, L'Ollivier C, Viguie C, Anaya L, Mary C, de Ponfilly G, Ranque S. Comparison of real-time PCR with conventional methods to detect dermatophytes in samples from patients with suspected dermatophytosis. J Microbiol Methods. 2013. 95: 218-222.

Weitzman I, Summerbell RC. The dermatophytes. Clin Microbiol Rev. 1995. 8: 240-259.

Zeng X, Kong F, Halliday C, Chen S, Lau A, Playford G, Sorrell TC. Reverse line blot hybridization assay for identification of medically important fungi from culture and clinical specimens. J Clin Microbiol. 2007. 45: 2872-2880. 